\title{
Combined Analysis of Results on Single and Multiple Contacts: Potting Soil, Sand and Clay Transfers to Cloth for the Estimate of Soil Adherence to Human Skin
}

\author{
Alesia C. Ferguson ${ }^{1}$, Zoran Bursac ${ }^{1} \&$ Wayne Johnson ${ }^{2}$ \\ ${ }^{1}$ College of Public Health, University of Arkansas for Medical Sciences, Arkansas, United States \\ ${ }^{2}$ Engineering Studies, Armstrong Atlantic University, Georgia, United States \\ Correspondence: Alesia C. Ferguson, College of Public Health, University of Arkansas for Medical Sciences, \\ Arkansas, United States. Tel: 1-501-526-6662. E-mail: aferguson@uams.edu
}

Received: March 25, $2013 \quad$ Accepted: May 5, $2013 \quad$ Online Published: May 10, 2013
doi:10.5539/enrr.v3n3p33
URL: http://dx.doi.org/10.5539/enrr.v3n3p33

\begin{abstract}
Humans can be exposed to contaminated soil and household dust via contact with environmental surfaces. A mechanical device was used to measure the transfer of soils from one surface to the other to provide estimates of adherence factors $\left(\mathrm{mg} / \mathrm{cm}^{2}\right)$ used in estimates of human exposure to contaminants found in soils/household dust. This paper presents the analysis and comparison for thetransfer of clay, potting soil, and sand from aluminum to cloth samples for single and multiple contacts under varying environmental and contact time and pressure conditions. Adherence for clay was over 73 times that of sand and over 114 times that of potting soil. Clay particles with their softer texture and finer composition compared to potting soil and sand, are more likely to compress and adhere to surfaces producing higher transfers. Contact time and temperature had no effect, however: contact pressure, soil loading on the aluminum surface, and environmental humidity did have an effect on soil transfer.
\end{abstract}

Keywords: human exposure assessment, soil contamination, soil adherence, transfer factors

\section{Introduction}

The contamination of soil with chemical byproducts, due to manufacturing and agricultural operations is prevalent throughout the United States, leads to exposures for children and adults under varying circumstances and scenarios. The variation of chemicals andtheir concentration outdoors are affected by the type and magnitude of industrial, commercial, mining, and agricultural activities in the area; wind and climate patterns affecting the transport and deposition mechanisms; the originating soil type by regions; location and motion of bodies of water; and land use development (Hendryx, Fodorko, \& Halverson, 2010; Isikli, Demir, Akar, Urer, Kalyoncu, \& Canbek, 2012; Jarup, 2003). Housing and occupational settings close to processes releasing contaminants (i.e., heavy metals, dioxins) pose greater health risks for residents and workers due to drift, track in, and take home of these contaminants (Hendryx et al., 2010; Kuo, Wang, Yeh, Kuo, \& Chou, 2010; Isikli et al., 2010; Nawrot et al., 2006).

House hold dust that accumulates over time and becomes persistent in the indoor environment is the main exposure source to a number of contaminants such as allergens, metals, pesticides, volatiles, and other mutagens or carcinogens for infants (Butte \& Heinzow, 2002; Hwang, Park, Young, \& Hammock, 2008; Roberts et al., 2009). The sources of contaminants in household dust can be from the outdoor sources listed above or indoor sources resulting from activities (e.g., smoking, pets in the home) or chemicals and products used in the home (e.g., new carpets, and sofas, pesticides, cleaning products) (Guo et al., 2012; Hwang et al., 2008; Thorne, Cohn, May, Arbes, \& Zeldin, 2009).

The recommendations for safe levels of indoor contaminants in soils and household dust are limited and typically based on sparse human exposure and dose factors, soil/dust characteristics, chemical characteristics, and other environmental factors. In an analysis of the very potent tetrachlorodibenzo-p-dioxin (TCDD), a level of $1 \mathrm{ppb}$ TEQ soil guidance was deemed a reasonable screening level for residential soil based on the most sensitive determinants of human dose and risk (Paustenback, Fehling, Scott, Harris, \& Kerger, 2006). In a different analysis on the relationship between exposure to lead-contaminated soil, the impact on public health, 
and past assessments, a blood lead level (BLL) rise in young children of 3-7 mcg/dl was observed for every 1000 ppm increase in soil or dust concentration (Centers for Disease Prevention and Control, 1992). There continues to be a need to determine safe levels of various contaminants in household dust and their potential effect on human health, where uptake can occur through the skin, inhalation, or ingestion. For contaminants where the main route of exposure is dermal, improved estimates of exposure based on human activity (i.e., number of contacts with surfaces) and exposure parameters such as adherence of soils and/or dust to the skin is important in improving risk estimates.

In an exposure assessment modeling approach, adherence values $\left(\mathrm{mg} / \mathrm{cm}^{2}\right)$ can be combined with contaminant concentration $\mathrm{pg} / \mathrm{mg}$ to determine the amount of contaminant on the area of skin $\left(\mathrm{pg} / \mathrm{cm}^{2}\right)$ as an estimate of dermal exposure. Dose estimates can be calculated by determining the uptake rate through the skin once the exposure estimate on the skin is derived. The document, Risk Assessment Guidance for Superfund, presents a more comprehensive approach [refer to Formula (1)] for the calculation of chemical dose from dermal contact with soil (Environmental Protection Agency [EPA], 1989).

$$
\mathrm{AD}=(\mathrm{CS} \times \mathrm{CF} \times \mathrm{SA} \times \mathrm{AF} \times \mathrm{ABS} \times \mathrm{EF} \times \mathrm{ED}) /(\mathrm{BW} \times \mathrm{AT})
$$

where:

$$
\begin{aligned}
& \mathrm{AD}=\text { Absorbed dose }(\mathrm{mg} / \mathrm{kg} / \mathrm{day}) \\
& \mathrm{CS}=\text { Chemical concentration in soil }(\mathrm{mg} / \mathrm{kg}) \\
& \mathrm{CF}=\text { Conversion factor }(10-6 \mathrm{~kg} / \mathrm{mg}) \\
& \mathrm{SA}=\text { Skin surface area available for contact }\left(\mathrm{cm}^{2} / \text { event }\right) \\
& \mathrm{AF}=\text { Soil-to-skin adherence factor }\left(\mathrm{mg} / \mathrm{cm}^{2}\right) \\
& \mathrm{ABS}=\text { Absorption factor (unitless) } \\
& \mathrm{EF}=\text { Exposure frequency (events } / \text { year) } \\
& \mathrm{ED}=\text { Exposure duration (years) } \\
& \mathrm{BW}=\text { Body weight }(\mathrm{kg}) \\
& \mathrm{AT}=\text { Averaging time (period over which exposure is averaged-days) }
\end{aligned}
$$

In a modeling approach, such as the equation above, it is necessary to determine the frequency of soil contact events per year (i.e., exposure frequency (EF)). This approach is on a macro-scale, but there are occasions within a short timeframe that multiple contacts with soil occur (e.g., 10 contacts with soil over a 10 minute time period). Thus, more accurate models must estimate the total loading of soil on skin based on a series of multiple contacts and limitations of adherence and loading at the skin surface to obtain a realistic estimate of exposure and dose. Models exist that use this micro-activity approach for estimating the loading of a soil (and therefore contaminant) on the skin surface (Canales, 2004; Zartarian, 1996; Zartarian et al., 2000). Reduction in the amount of soil on the skin is also considered based on removal events at the skin surface (e.g., hand washing, and wiping events) along with consideration of maximum loads feasible on the skin surface.

The adherence of clays, resulting from single contacts, has been previously presented in relation to artisans exposed to clays contaminated with dioxins (Ferguson, Bursac, Johnson, \& Davis, 2012). Adherence studies of sand and potting soils were also previously published to provide data needed to model children's dermal exposure in and around the home (Ferguson, Bursac, Coleman, Biddle, \& Johnson, 2008; Ferguson, Bursac, Coleman, Biddle, \& Johnson, 2009 a, b; Ferguson, Coleman, Bursac, \& Johnson, 2009c). Adherence measures for multiple contacts for clay are presented for the first time in this paper. In addition, this paper compares the mass loading of three types of soils to cloth (representing skin) for single and multiple contacts and can aid the researcher in modeling efforts to estimate exposure to contaminants in soils or household dust where adherence values in $\mathrm{mg} / \mathrm{cm}^{2}$ is needed. Clay, sand, and potting soil represent varied soil matrices with potentially different adherence potentials to the human skin as afunction of texture, moisture, and size structure. In applying adherence values for soils from any study, the exposure modeler should be aware of the diverse exposure scenarios, soil types/mixtures, and the potentially varied distribution of contaminants in those soils. The distribution of contaminants is not only based on original sources of contaminants, but on their ability to bind, break down, or leach in the various soil types (Engle, Cogger, \& Stevens, 1991). Here cloth is used to represent human skin (as has been done in other adherence studies of contaminant exposures), and can provide a comparison for various soil types. Past experiments from this group have used cadaver skin for adherence 
experiments. It is recognized that the characteristics of cloth and skin vary and can influence adherence.

\section{Method}

Experiments for mass transfer of soil types were conducted using a mechanical chamber designed to control and measure the contact pressure and duration of contact between two plates. Mass transfer was measured from an $8.97 \mathrm{~cm}^{2}$ aluminum plate laden with clay, sand, or potting soil to cloth samples attached to an actuated plate. Temperature and relative humidity probes were used to closely monitor and record the environmental conditions in the chamber. Previous results were published for adherence experiments conducted with potting soil and sand (Ferguson et al., 2008; Ferguson et al., 2009 a, b, c) and for clay based on single contacts (Ferguson et al., 2012). Those past experiments were combined with these multiple clay experiments to look at single, multiple, and total transfers for the overlapping pressures of 20,30,40, and $50 \mathrm{kPa}$ (60 $\mathrm{kPa}$ was excluded for sand and potting soil), and for 10,30, and 50 seconds (60 seconds was excluded for sand and potting soil). Only adherence for cloth from aluminum surfaces was analyzed for the soil models bringing the total number of experiments to 236 . The adherence material of skin and the adherence surface of carpet were also excluded for sand and soil, based on no comparison with contacts for clay. Previously, for potting soil and sand adherence tests, the soil sizes of $<139.7$ $\mu \mathrm{m}$ and from 139.7 up to $381 \mu \mathrm{m}$ were analyzed separately; these two sand and soil sizes were analyzed separately and together to determine any difference in adherence results. Chamber temperature, chamber relative humidity, and soil mass before and after contact were recorded in all experiments.Further descriptions for potting soil and sand can be found in the previous publications for single and multiple contacts for adherence to cloth and human skin from carpet and aluminum surfaces (Ferguson et al., 2008; Ferguson et al., 2009 a, b, c).

\subsection{Mechanical Chamber}

The chamber consists of an outer and inner housing; air cooling, heating, and humidification devices; a changeable pneumatic cylinder and associated equipment and various temperature, pressure, and relative humidity transducers. National Instruments is the manufacturer of a USB 6009 data acquisition device (DAQ) which was used along with LabVIEW Virtual Instruments (VIs) to interface all instruments in the chamber with a personal computer. LabVIEWVIs provided a user interface to the instruments via the USB 6009 and recorded all sensor information (temperature and relative humidity) over the user-specified and chamber-controlled contact times and pressures. Chamber operation and use of the LabVIEW interface to control and record experimental parameters is well described in all previous experimental result papers and results and on the chamber design (Johnson, Ferguson, Hager, Sanou, \& Shenoda, 2006; Johnson, Ferguson, Hager, Sanou, \& Shenoda, 2007).

\subsection{Contact Pressure and Time Range}

Contact pressures (i.e., force applied over a surface area) and time of contact can potentially affect the mass transfer of chemicals. Some contact pressures were indicated by pediatric and occupational therapy literature for grip pressures exerted by children and adults (Dunn, 1993; Gurram, Gouw, \& Rakheja, 1993; Link, Lukens, \& Bush, 1995; Robertson \& Dietz, 1988). The motions and pressures involved in making clay pottery might be expected to include a wider range of contact pressures over those encountered for situations of sand and potting soil contact (e.g., children playing in playground and around the home). Contact times can vary broadly for various contact scenarios encountered for these soil types, but increased contact times beyond a maximum point may not affect transfer rates, only the chemical uptake into the skin.

\subsection{Clay, Sand, Soil and Cloth Preparation}

As a comparison with soil transfer to human cadaver skin, cotton sheets were purchased from a fabric store. Soil transfer to human cadaver skin was previously conducted for sand and potting soil (Ferguson et al., 2008; Ferguson et al., 2009 a, b, c), but, however, were not performed for clay contacts. The cotton sheets were 200 thread count, $100 \%$ combed cotton sateen, with woven strips (Gramercy Park Sheets, New York, NY, USA). These were also cut into appropriate sizes and attached to the $8.97 \mathrm{~cm}^{2}$ circular upper plate using o-rings. The clay was obtained through the Arkansas Art Center located in downtown Little Rock, AR. Within the studio section of the art center, artisans and students use this clay to mix with other materials to make pottery and related products. Dermal exposure can occur during the handling of clay containing dioxins. Dioxins can also be released for inhalation exposure during the kiln process where heat is applied to the finished products (Ferrario, Byrne, \&Schaum, 2004; National Center for Environmental Assessment, 2008).

Play sand and lawn soil were purchased from Home Depot. The play sand is manufactured by LaFarge, North America (Pavestone Item \# 55141), while the enriched lawn potting soil (i.e.: made of peat moss, a wetting agent, and fertilizer) is manufactured by Scotts, Inc. (product \# 79259750). Sand and lawn soil were placed in open 
buckets to equilibrate with room conditions. Both were then dry-sieved to obtain two sizes $<139.7 \mu \mathrm{m}$ and $<$ $381.0 \geq 139.7 \mu \mathrm{m}$, due to the apparent wide distribution of particle sizes. The authors have previously noted that the majority of the particle size distributions of the original sand and potting soil ranged between 66.4 to $139 \mu \mathrm{m}$ (95.24\%) for sand and was greater than $1524 \mu \mathrm{m}(72.92 \%)$ for potting/lawn soil (Ferguson et al., 2007). Clay, sand or soil were not wetted. Humidity in the chamber was recorded and statistical correlations were made between this recorded humidity and adherence values.

\subsection{Experimental Procedure}

The experimental procedure was the same for each soil type. Clay, sand, or potting soil was distributed over $96.05 \mathrm{~cm}^{2}$ aluminum samples placed over the bottom plate with full coverage in the center over the $8.97 \mathrm{~cm}^{2}$ contact area. The chamber was cleaned and dusted with a static brush between experiments to make sure it was free of any clay particles. The aluminum samples with loaded clay, sand, or potted soil were weighed on an analytical Mettler Toledo balance (Columbus, OH, USA: model \# AB-265-S) and then placed into the bottom plate of the chamber (this is 'Mass 1'). The upper plate with an attached cotton sheet was connected to the pneumatic cylinder within the chamber. After controlled contact was achieved between the upper and lower plates and recorded by the Virtual Instrument, the aluminum sample loaded with clay, sand, or potting soil was removed from the chamber and again weighed to obtain the difference (i.e., Mass 2). This difference ('Mass 1''Mass 2') corresponded to the amount of soil that adhered to the cotton sheet, and can be considered 'First Transfer'. For 'Second Transfer', the same aluminum sample loaded with the soil type (i.e., 'Mass 2') was placed carefully back in the chamber and a second controlled contact between the upper plate and lower plate was initiated and recorded by the Virtual Instrument under the same pressure and time of contact parameters as the first contact. The soil loaded aluminum sample was then removed from the chamber and again weighed to obtain 'Mass 3'. The difference (negative or positive) between 'Mass 2' and 'Mass 3' corresponded to the amount of soil that adhered to or was removed from the same cotton sheet for 'Second Transfer'. 'Total Transfer' is 'Mass 1'-'Mass 3'.

\subsection{Statistical Analysis}

All statistical analyses were performed using SASv9 (SAS Institute Inc., Cary, NC). The logarithmic transformation of the soil mass transfer amounts (i.e., mass adherence values) was performed to normalize the distribution. Descriptive statistics, including means and standard deviations for continuous variables and proportions for categorical variables were generated. Testing equality of means for clay mass adherence between individual experimental conditions was done using two sample t-tests and one-way analysis of variance (ANOVA) with Tukey-Kramer adjustment for multiple comparisons. Distribution of soil mass adherence was tested for normality using Kolmogorov-Smirnov test. The effect of experimental conditions on the transfer of soil as well as interactions was determined using two variations of a fixed effects model; in the first model there are three types of soils. Sand and potting soil are further separated by two particle sizes in the second model [refer to Formulas (2) and (3)].

$$
\begin{gathered}
\log (\text { transfer })=\mathrm{b} 0+\mathrm{b} 1(\text { time })+\mathrm{b} 2(\text { pressure })+\mathrm{b} 3(\text { clay } / \text { sand } / \text { soil })+\mathrm{b} 4(\text { amountbefore }) \\
+\mathrm{b} 5(\text { temperature })+\mathrm{b} 6(\text { humidity })
\end{gathered}
$$

And

$$
\begin{aligned}
& \log (\text { transfer })=b 0+b 1(\text { time })+b 2(\text { pressure })+b 3(\text { clay } / \text { sand small } / \text { sand large/potting soil } \\
& \text { small/potting soil large })+b 4(\operatorname{amount}(3) \text { before })+b 5(\text { temperature })+b 6 \text { (humidity })
\end{aligned}
$$

This model accounted for the amount of soil before the transfer as well as the relative humidity and temperature of the chamber. Estimated adjusted means for experimental conditions were exponentiated back to express them in the original units. All of the results were considered significant at the 0.05 alpha level.

\section{Results}

Results will be first presented for the First Transfer which is defined as the mass transfer of a soil type after the first contact between the plate with the cloth sample and the plate with the aluminum surface loaded with the soil type (i.e. 'Mass 2'-'Mass 1'). Results will then be presented for the Second Transfer, defined as the mass transfer of a soil type after a second contact between the same plate and cloth sample and the same plate with the aluminum surface loaded with the soil type (i.e., 'Mass 3'-'Mass 2'). Lastly, results will be presented for the Total Transfer which is the addition of the amount transferred in the first contact and the amount transferred in the second contact (i.e., 'Mass 3'-'Mass 1'). Table 1 summarizes a number of mass transfer variables across all soil types for 236 combined mass transfer experiments, where each experiment involves two contacts between a 
surface containing the soil media and the cloth samples used to represent human skin. The number of experiments for sand and potting soil were 95 and 93, respectively, where two soil sizes were tested for both soil types. More information on the size distribution contained in the sand and potting soils used can be found in a previous publication (Ferguson et al., 2009b). A total of 48 experiments were performed using clay without any size separation due to the consistent and fine texture of the clay. Temperature across the 236 experiments was $77.8 \pm 0.9^{\circ} \mathrm{F}$ and average relative humidity was $28.9 \pm 9.2 \%$.

Table 1. Means analysis for mass transfer

\begin{tabular}{llllll}
\hline Parameter & $\begin{array}{l}\text { Mean } \\
\text { transfer }\end{array}$ & $\begin{array}{l}\text { Median } \\
\text { transfer }\end{array}$ & $\begin{array}{l}\text { Standard } \\
\text { deviation }\end{array}$ & $\begin{array}{l}\text { Minimum } \\
\text { transfer }\end{array}$ & $\begin{array}{l}\text { Maximum } \\
\text { transfer }\end{array}$ \\
\hline First Transfer & 8.71 & 1.95 & 13.36 & 0.01 & 44.10 \\
Log(First Transfer) & 0.93 & 0.67 & 1.69 & -4.61 & 3.77 \\
Second Transfer & 0.64 & 0.13 & 5.18 & -18.32 & 69.75 \\
Total Transfer & 9.35 & 2.13 & 14.83 & 0.00 & 71.61 \\
Log (Total Transfer) & 1.00 & 0.76 & 2.61 & -3.91 & 4.27 \\
Mass Soil Before & 2934.13 & 2861.08 & 761.19 & 1736.47 & 6360.50 \\
Mass Soil After & 2925.42 & 2848.43 & 753.12 & 1733.22 & 6321.90 \\
Mass Soil After 2 ${ }^{\text {nd }}$ Contact & 2924.78 & 2857.47 & 752.39 & 1733.00 & 6316.20 \\
Humidity $(\%)$ & 28.94 & 25.50 & 9.24 & 15.10 & 48.25 \\
Temperature $\left({ }^{\circ} \mathrm{F}\right)$ & 77.77 & 77.70 & .91 & 75.40 & 81.00 \\
\hline
\end{tabular}

Note: $\left(\mathrm{mg} / 8.97 \mathrm{~cm}^{2}\right.$ area $)$ for all soil types combined $(\mathrm{n}=236)$ : non-adjusted data. 
Table 2. Means analysis for mass transfer by soil type

\begin{tabular}{|c|c|c|c|c|c|}
\hline Soil Type & Measure & $\begin{array}{l}\text { Mean } \\
\text { transfer }\end{array}$ & $\begin{array}{l}\text { Standard } \\
\text { deviation }\end{array}$ & $\begin{array}{l}\text { Minimum } \\
\text { transfer }\end{array}$ & $\begin{array}{l}\text { Maximum } \\
\text { transfer }\end{array}$ \\
\hline Sand & First Transfer & 2.21 & 2.22 & 0.09 & 11.92 \\
\hline \multirow[t]{7}{*}{$\mathrm{n}=95$} & Log (First Transfer) & 0.36 & 0.99 & -2.41 & 2.48 \\
\hline & Second Transfer & 0.64 & 7.23 & -4.07 & 69.75 \\
\hline & Total Transfer & 2.85 & 7.44 & 0.10 & 71.61 \\
\hline & Log (Total Transfer) & 0.43 & 0.95 & -2.30 & 4.27 \\
\hline & Mass Soil Before & 2775.26 & 647.39 & 1959.96 & 3826.65 \\
\hline & Mass Soil After & 2773.05 & 648.45 & 1952.94 & 3826.31 \\
\hline & Mass Soil After $2^{\text {nd }}$ Contact & 2772.41 & 647.92 & 1953.30 & 3826.01 \\
\hline Potting Soil & First Transfer & 2.37 & 3.19 & 0.01 & 24.74 \\
\hline \multirow[t]{7}{*}{$\mathrm{n}=93$} & Log (First Transfer) & 0.19 & 1.41 & -4.61 & 3.21 \\
\hline & Second Transfer & -0.17 & 2.12 & -18.32 & 4.84 \\
\hline & Total Transfer & 2.20 & 2.24 & 0.00 & 12.22 \\
\hline & Log (Total Transfer) & 0.27 & 1.20 & -3.91 & 2.50 \\
\hline & Mass Soil Before & 2599.26 & 406.05 & 1736.47 & 3732.09 \\
\hline & Mass Soil After & 2596.89 & 405.65 & 1733.22 & 3731.46 \\
\hline & Mass Soil After $2^{\text {nd }}$ Contact & 2597.06 & 405.75 & 1733.00 & 3731.94 \\
\hline Clay & First Transfer & 33.86 & 7.19 & 10.05 & 44.10 \\
\hline \multirow[t]{7}{*}{$\mathrm{n}=48$} & Log (First Transfer) & 3.49 & 0.30 & 2.31 & 3.79 \\
\hline & Second Transfer & 2.21 & 4.15 & -2.71 & 27.60 \\
\hline & Total Transfer & 36.07 & 7.95 & 11.80 & 57.70 \\
\hline & Log (Total Transfer) & 3.55 & 0.29 & 2.47 & 4.06 \\
\hline & Mass Soil Before & 3897.39 & 718.03 & 2752.70 & 6360.50 \\
\hline & Mass Soil After & 3863.53 & 716.67 & 2716.10 & 6321.90 \\
\hline & Mass Soil After $2^{\text {nd }}$ Contact & 3861.32 & 716.51 & 2713.30 & 6316.20 \\
\hline
\end{tabular}

Note: transfer expressed as $\mathrm{mg} / 8.97 \mathrm{~cm}^{2}$ area, $\mathrm{n}=236$, and non-adjusted data.

\subsection{First Transfer}

The mean transfer to cloth samples before log transformation for adherence of sand, potting soil, and clay combined from aluminum surface based for the First Transfer was $8.71 \pm 13.3 \mathrm{mg} / 8.97 \mathrm{~cm}^{2}$. The average sand, potting soil, or clay used initially on the aluminum surface was $2934.1 \pm 761.2 \mathrm{mg}$. Kolmogorov-Smirnov test for normality again showed that the distribution of the outcome (sand/soil/clay transfer) was skewed $(p<0.01)$ warranting a $\log$ transformation. Transformation of the outcome (soil transfer) reasonably normalized the distribution. After log transformation, log mass transfer for First Transfer was on average $0.93 \pm 1.7 \mathrm{mg} / 8.97 \mathrm{~cm}^{2}$. Table 2, shows a breakdown for First Transfer before and after log transformation for the different soil types. In the univariate analysis for parameter effect on First Transfer, adherence of both soil sizes of sand and potting soil showed significance over clay in the model $(\mathrm{p}<0.0001)$ as seen in Table 3 . When soil sizes are separated for sand and potting soil, the mean $\log$ transfer for sand for soil size $139.7-381 \mu \mathrm{m}$ was- $0.17 \mathrm{mg} / 8.97 \mathrm{~cm}^{2}$ and for soil size of $<139.7 \mu \mathrm{m}$ was $0.91 \mathrm{mg} / 8.97 \mathrm{~cm}^{2}$, while for potting soil for soil size $139.7-381 \mu \mathrm{m}$ was- 0.31 $\mathrm{mg} / 8.97 \mathrm{~cm}^{2}$ and for soil size of $<139.7 \mu \mathrm{m}$ was $0.70 \mathrm{mg} / 8.97 \mathrm{~cm}^{2}$. Both types of soils show greater adherence for the smaller sized particles. Neither contact pressure nor contact time showed any effect on adherence for the soil types in the univariateanalysis. 
Table 3. Univariate analysis

\begin{tabular}{|c|c|c|c|c|c|c|}
\hline Effect & $\begin{array}{c}\text { Mean for } \\
\text { First } \\
\text { Transfer } \\
\text { over a } 8.97 \\
\mathrm{~cm}^{2} \text { area }\end{array}$ & $\begin{array}{l}\text { Standard } \\
\text { deviation }\end{array}$ & p-value & $\begin{array}{l}\text { Mean for Total } \\
\text { Transfer over a } \\
8.97 \mathrm{~cm}^{2} \text { area }\end{array}$ & $\begin{array}{l}\text { Standard } \\
\text { deviation }\end{array}$ & p-value \\
\hline \multicolumn{7}{|l|}{ Pressure $(\mathrm{kPa})$} \\
\hline 20 & 0.82 & 1.84 & 0.1706 & 1.00 & 1.76 & 0.4472 \\
\hline 30 & 0.94 & 1.69 & 0.3335 & 0.85 & 1.77 & 0.2099 \\
\hline 40 & 0.70 & 1.88 & 0.0769 & 0.93 & 1.61 & 0.3132 \\
\hline 50 & 1.25 & 1.30 & & 1.23 & 1.32 & \\
\hline \multicolumn{7}{|l|}{ Time in Seconds (s) } \\
\hline 10 & 0.84 & 1.64 & 0.7289 & 0.82 & 1.61 & 0.3793 \\
\hline 30 & 1.00 & 1.80 & 0.8202 & 1.15 & 1.60 & 0.6926 \\
\hline 50 & 0.94 & 1.66 & & 1.04 & 1.64 & \\
\hline $\begin{array}{l}\text { Soil Types Sand } \\
(139.7-381 \mu \mathrm{m})\end{array}$ & -0.17 & 0.92 & $<0.0001$ & 0.05 & 1.00 & $<0.0001$ \\
\hline Sand $(<139.7 \mu \mathrm{m})$ & 0.91 & 0.72 & $<0.0001$ & 0.82 & 0.71 & $<0.0001$ \\
\hline $\begin{array}{l}\text { Potting Soil } \\
(139.7-381 \mu \mathrm{m})\end{array}$ & -0.31 & 1.52 & $<0.0001$ & -0.39 & 1.27 & $<0.0001$ \\
\hline \multicolumn{7}{|l|}{ Potting Soil } \\
\hline$(<139.7 \mu \mathrm{m})$ & 0.70 & 1.08 & $<0.0001$ & 0.69 & 0.96 & $<0.0001$ \\
\hline Clay & 3.49 & 0.30 & & 3.55 & 0.29 & \\
\hline
\end{tabular}

Note: transfer expressed as $\mathrm{mg} / 8.97 \mathrm{~cm}^{2}$ area, for parameter (i.e.: pressure, time, and soil type) effects on 'First Transfer' and 'Total Transfer' based upon Lognormal values.

Table 4 shows the adjusted means (exponentiated back to the original units) for adherence for sand, potting soil, and clay, where adherence of both soil sizes of sand and potting soil again showed significance over clay in the multivariate analysis $(\mathrm{p}<0.0001)$. Table 4 also shows the highest soil mass transfer of $3.86 \mathrm{mg} / 8.97 \mathrm{~cm}^{2}$ for the contact pressure of $50 \mathrm{kPa}$ in the multivariate analysis. No significance in the effect of contact time on mass transfer was seen in the multivariate analysis. Relative humidity in the chamber $(\mathrm{p}<0.0215)$ and soil on the surface before $(\mathrm{p}<0.006)$ were inversely associated with mass transfer when the soil types were separated by sand, soil and clay in the model. However, only relative humidity $(\mathrm{p}<0.0001)$ showed an effect when the soil particles sizes for sand and potting soil were separated in the model. 
Table 4. Adjusted means

\begin{tabular}{lcccc}
\hline Effect & $\begin{array}{c}\text { Mean for First } \\
\text { Transfer over } \\
\text { an } 8.97 \mathrm{~cm}^{2} \\
\text { area }\end{array}$ & p-value & $\begin{array}{c}\text { Mean for Combined } \\
\text { Transfer over an } 8.97 \\
\mathrm{~cm}^{2} \text { area }\end{array}$ & p-value \\
\hline Pressure $(\mathrm{kPa}) 20$ & 2.03 & 0.0005 & 2.48 & 0.0139 \\
30 & 2.22 & 0.0026 & 2.01 & 0.0002 \\
40 & 2.23 & 0.0016 & 2.78 & 0.0624 \\
50 & 3.86 & & 3.71 & \\
Time in Seconds $(\mathrm{s}) 10$ & 2.40 & 0.7660 & 2.33 & 0.2029 \\
30 & 2.57 & 0.8993 & 2.97 & 0.6150 \\
50 & 2.52 & & 2.77 & \\
Soil Groups Sand $(139.7-381 \mu \mathrm{m})$ & 0.64 & $<0.0001$ & 0.82 & $<0.0001$ \\
Sand $(<139.7 \mu \mathrm{m})$ & 2.05 & $<0.0001$ & 1.68 & $<0.0001$ \\
Potting Soil $(139.7-381 \mu \mathrm{m})$ & 0.47 & $<0.0001$ & 0.52 & $<0.0001$ \\
Potting Soil $(<139.7 \mu \mathrm{m})$ & 1.84 & $<0.0001$ & 1.70 & $<0.0001$ \\
Clay & 85.04 & & 112.29 & \\
\hline
\end{tabular}

Note: transfer expressed as $\mathrm{mg} / 8.97 \mathrm{~cm}^{2}$ area, from multivariate regression model for 'First Transfer' and 'Second Transfer'.

In summarizing First Transfer, the highest mass transfers were seen for clay particles of $33.86 \mathrm{mg} / 8.97 \mathrm{~cm}^{2}$ compared to $2.21 \mathrm{mg} / 8.97 \mathrm{~cm}^{2}$ for sand and $2.37 \mathrm{mg} / 8.97 \mathrm{~cm}^{2}$ for potting soil before any adjustment or particle size comparison were made (Table 2). Therefore, the adherence for clay was significantly different at over 15 times that of sand and over 14 times that of potting soil. After model adjustment for skewness, (i.e., reflecting a high degree of variability in the adherence values) this difference rose to $85.68 \mathrm{mg} / 8.97 \mathrm{~cm}^{2}\left(8.53 \mathrm{mg} / \mathrm{cm}^{2}\right)$ for clay, compared to $1.18 \mathrm{mg} / 8.97 \mathrm{~cm}^{2}\left(0.13 \mathrm{mg} / \mathrm{cm}^{2}\right)$ for sand and $0.89 \mathrm{mg} / 8.97 \mathrm{~cm}^{2}\left(0.10 \mathrm{mg} / \mathrm{cm}^{2}\right)$ for potting soil (Table 4). Therefore, the adherence for clay was over 73 times that of sand and over 114 times that of potting soil. Clay particles, with their softer texture and fine composition, likely compress and adhere to surface and to adjacent clay particles producing higher transfers. Although, adherence of the smaller particle sizes for sand and potting soil tend to be greater than the larger particle sizes, the adherence is still well below that of the clay particles (see Table 4). A previous paper from the authors summarized soil and soil adherence studies from other researchers (Ferguson et al., 2009c). Those past studies have reported values ranging from 0 to $21 \mathrm{mg} / \mathrm{cm}^{2}$, with most values skewed in the 0 to $1 \mathrm{mg} / \mathrm{cm}^{2}$ range and so clay transfer tends to be in the higher range. Again, other soil-skin adherence studies in the field show large variability in experimental conditions, measurement techniques, and soil type(s) used, thus complicating true comparisons of adherence values. 
Table 5. Analyses for parameter effects

\begin{tabular}{llllll}
\hline Effect & $\begin{array}{l}\text { Mean } \\
\text { Transfer }\end{array}$ & $\begin{array}{l}\text { Standard } \\
\text { Deviation }\end{array}$ & Minimum & Maximum & p-value \\
\hline Pressure $(\mathrm{kPa}) 20$ & 1.33 & 0.69 & -0.04 & 2.70 & 0.2814 \\
30 & -0.03 & 0.71 & -1.43 & 1.37 & 0.7706 \\
40 & 0.89 & 0.68 & -0.45 & 2.24 & 0.5030 \\
50 & 0.26 & 0.68 & -1.07 & 1.59 & \\
Time in seconds $(\mathrm{s}) 10$ & 0.35 & 0.59 & -0.81 & 1.51 & 0.2932 \\
30 & 0.25 & 0.58 & -0.90 & 1.40 & 0.2367 \\
50 & 1.23 & 0.59 & 0.08 & 2.39 & \\
Soil GroupsSand $(139.7-381 \mu \mathrm{m})$ & 1.70 & 0.87 & -0.01 & 3.41 & 0.6255 \\
Sand $(<139.7 \mu \mathrm{m})$ & -0.62 & 1.05 & -2.70 & 1.44 & 0.1868 \\
Potting Soil $(139.7-381 \mu \mathrm{m})$ & -0.16 & 0.98 & -2.10 & 1.78 & 0.2493 \\
Potting Soil $(<139.7 \mu \mathrm{m})$ & -0.55 & 0.86 & -2.24 & 1.14 & 0.1465 \\
Clay & 2.69 & 1.77 & -0.80 & 6.19 & \\
\hline
\end{tabular}

Note: transfer expressed as $\mathrm{mg} / 8.97 \mathrm{~cm}^{2}$ area, on 'Second Transfer' for clay, sand, and potting soil transfers in the Mixed Procedure.

\subsection{Second Transfer}

Table 5 shows the results for the soil mass transfer amounts after the second contact. Second Transfer following the initial transfer is quite variable with a transfer of $0.64 \mathrm{mg} / 8.97 \mathrm{~cm}^{2}$ (std. dev. $7.22 \mathrm{mg} / 8.97 \mathrm{~cm}^{2}$ ) for sand, a transfer of $-0.17 \mathrm{mg} / 8.97 \mathrm{~cm}^{2}$ (std. dev. $2.12 \mathrm{mg} / 8.97 \mathrm{~cm}^{2}$ ), and a transfer of $2.21 \mathrm{mg} / 8.97 \mathrm{~cm}^{2}$ (std. dev. 4.15 $\mathrm{mg} / 8.97 \mathrm{~cm}^{2}$ ) for clay. Again, clay adherence is the largest on average for all pressures and times. No significant difference was observed in the mixed procedure for the mass transfer across the soil types for Second Transfer (Table 5). Pressure and time of contact was also not shown to have a significant effect on the mass transfer for the second contact (all $\mathrm{p}>0.05$ ). Likewise relative humidity and temperature did not significantly affect the amount of transfer for the Second Transfer.

\subsection{Total Transfer}

Table 1 also shows summaries for Total Transfer across all soil types for 236 combined mass transfer experiments. The mean total transfer (i.e., mass transfer of soil after two sequential contacts) to cloth samples before $\log$ transformation for adherence of all soil types combined from aluminum surface was $9.35 \pm 14.8$ $\mathrm{mg} / 8.97 \mathrm{~cm}^{2}$. After $\log$ transformation, log mass transfer for Total Transfer was on average $1.00 \pm 2.61 \mathrm{mg} / 8.97$ $\mathrm{cm}^{2}$. Table 2, also shows a breakdown for Total Transfer before and after log transformation for the different soil types. In the univariate analysis for parameter effect on Total Transfer, adherence of both soil sizes of sand and potting soil showed significance over clay in the model $(\mathrm{p}<0.0001)$ as seen in Table 3. Again, both types of soil show greater adherence, even after the second transfer for the smaller sized particles. Table 4 shows the adjusted means (exponentiated back to the original units) for adherence for sand, potting soil, and clay after the second contact (i.e., total transfer), where adherence of both soil sizes of sand and potting soil again showed significance over clay in the multivariate analysis $(\mathrm{p}<0.0001)$.

The overall change after model adjustment from First Transfer to Total Transfer, following a second contact was a $32 \%$ increase for clay, an $18 \%$ decrease for the smaller sand particles, but an increase of $28 \%$ for the larger sand particles, and a $7.6 \%$ decrease for the smaller potting soil particles, but a $10.6 \%$ increase for the larger potting soil particles (Table 4). Negative transfer can occur during the second contact and is feasible in human contact scenarios wheresoil can transfer back to the surface upon contact. Table 4 also shows the highest total soil mass transfer of $3.71 \mathrm{mg} / 8.97 \mathrm{~cm}^{2}$ occurred for the higher pressure of $50 \mathrm{kPa}$. In the multivariate analysis, the lower adherence of $2.48 \mathrm{mg} / 8.97 \mathrm{~cm}^{2}$ at $20 \mathrm{kPa}$, and $2.01 \mathrm{mg} / 8.97 \mathrm{~cm}^{2}$ at $30 \mathrm{kPa}$ showed significant difference in the model to the total mass soil transfer at $50 \mathrm{kPa}$ of $3.71 \mathrm{mg} / 8.97 \mathrm{~cm}^{2}(\mathrm{p}=0.0139,0.0002$, respectively). There was only moderate significance for the transfer at $40 \mathrm{kPa}$ of $2.78 \mathrm{mg} 8.97 \mathrm{~cm}^{2}$ over the transfer at $50 \mathrm{kPa}(\mathrm{p}=0.0624)$. No significance in the effect of time of contact on adherence for Total Transfer 
was seen in the multivariate analysis.

Similar to First Transfer, relative humidity in the chamber $(p<0.0019)$ and soil on surface before $(p<0.0004)$ were inversely associated with mass transfer amount when the soil types were separated by sand, soil, and clay in the model for Total Transfer. Again, chamber relative humidity $(\mathrm{p}<0.0001)$ still showed an inverse effect on mass transfer amount when the soil particles sizes for sand and potting soil were separated in the model. This is an unexpected result, as higher relative humidity levels were previously associated with higher mass transfers when sand and potting soils were analyzed in previous papers by this group. Clay particles may be affecting results by clumping together on surfaces resulting in lower transfer to the cloth. Additional experiments are needed to determine the relationship between the air humidity, measurements of soil moisture content, and its effect on adherence to skin.

This paper presents a statistical analysis of the mass transfer of three soil types from an aluminum surface to cloth samples for a limited and comparable dataset along with new results of multiple contacts for clay transfers. Previous papers presented transfer of soil and sand to human cadaver skin (i.e., a better representative of live skin) and demonstrated greater mass transfers compared to cloth (Ferguson et al., 2008; Ferguson et al., 2009 a, $\mathrm{b}, \mathrm{c})$. It is expected, therefore, that mass transfer of clay particles to human skin will also be greater. There is limited information in the literature concerning the adherence of clays to the human skin, and the information here can be used to expand the dataset for clay adherence for single and multiple contacts.

\section{Conclusion}

In general, this study found higher transfer of clays to cloth, compared to sand and soil. Results also showed higher transfer for the smaller sized particles of both sand and potting soil. Time was not shown to have an effect in this combined analysis, whereas pressure and humidity had some effect. Additional experiments using the adherence chamber have also been conducted to look at transfer from aluminum and carpet surfaces for soil and sand and from both cloth and human cadaver skin (Ferguson et al., 2009 a, c). Previous results showed that humidity did increase the adherence of those soils to human skin but not to cloth, and that there was less adherence from carpet than from an aluminum surface. Readers are encouraged to explore these papers to look at additional nuances and difference between soil types and surfaces. Additional conditions of adherence can be further explored including mixtures of soil types, moisture conditions within the soil, and contact dynamics (e.g., sliding and rubbing). Adherence data is important for children playing on various soil types in and around the house, for the clay artisans who handle mixes containing ball clay, and for other occupations and hobbies where dermal contact is likely (e.g., lawn care and gardening), and can be used in a modeling analysis to estimate loading on skin after relevant exposure events.

\section{References}

Butte, W., \& Heinzow, B. (2002). Pollutants in house dust as indicators of indoor contamination. Reviews of Environmental Contamination and Toxicology, 175, 1-46.

Canales, R. A. (2004). The cumulative and aggregate simulation of exposure framework. Unpublished doctoral dissertation, Stanford University, Stanford, CA.

Centers for Disease Prevention and Control (1992). Impact of lead contaminated soil on public health. Retrieved from http://wonder.cdc.gov/wonder/prevguid/p0000015/p0000015.asp

Dunn, W. (1993). Grip strength of children aged 3 to 7 years using a modified sphygmomanometer: Comparison of typical children and children with rheumatic disorders. American Journal of Occupational Therapy, 47, 421-428. http://dx/doi.org/10.5015/ajot.47.5.421

Engle, C. F., Cogger, C. G., \& Stevens, R. G. (1991). Role of soil in groundwater protection. Cooperative Extension Publications of Washington State University. Retrieved from http://cru.cahe.wsu.edu/CEPublications/eb1633/eb1633.html (Feb. 17, 2012).

Environmental Protection Agency (EPA). (1989). Risk assessment guidance for superfund (Volume I) in Human Health Evaluation Manual (Part A). Retrieved from http://www.epa.gov/oswer/riskassessment/ragsa/

Ferguson, A., Bursac, Z., Coleman, S., Biddle, D., \& Johnson, W. (2008). Soil-skin adherence from carpet: Use of a mechanical chamber to control contact parameters. The Journal of Environmental Health, 43(12), 1451-1458. http://dx/doi.org/10.1080/10934520802232253

Ferguson, A., Bursac, Z., Coleman, S., Biddle, D., \& Johnson, W. (2009a). Comparisons of computer controlled chamber measurements for soil-skin adherence from aluminum and carpet surfaces. Environmental Research, 109, 207-214. http://dx/doi.org/10.1016/j.envies.2008.12.011 
Ferguson, A., Bursac, Z., Johnson, W., \& Davis, J. (2012). Computer-controlled chamber measurement for clay adherence relevantfor potential dioxin exposure through skin. Journal of Environmental Science and Health, Part A, 47(3), 382-388. http://dx.doi.org/10.1080/10934529.2012.646098

Ferguson, A., Coleman, S., Biddle, D., Bursac, Z., \& Johnson, W. (2009b). In-vitro soil adherence for dermal exposure using a controlled mechanical chamber. Journal of Applied Sciences Research, 5(2), 232-243.

Ferguson, A., Coleman, S., Bursac, Z., \& Johnson, W. (2009c). Computer controlled chamber measurements for multiple contacts for soil-skin adherence from aluminum and carpet surfaces. Human and Ecological Risk Assessment, 15(4), 811-849. http://dx.doi.org/10.1080/10807030903051283

Ferrario, J., Byrne, C., \&Schaum, J. (2004). An assessment of dioxin levels in processed ball clay from the United States. Organohalogen Compounds, 66, 1639-1644.

Guo, W., Park, J. S., Wang, Y., Gardner, S., Baek, C., Petreas, M., \& Hooper, K. (2012). High polybrominated diphenylether levels in California house cats: House dust a Primary Source? Environmental Toxicology and Chemistry, 31(2), 301-306. http://dx.doi.org/10.1002/etc.1700

Gurram, R., Gouw, G. J., \&Rakheja, S. (1993). Grip pressure distribution understatic and dynamic loading. Experimental Mechanics, 33(3), 169-173. http://dx.doi.org/10.1007/BF02322568

Hendryx, M., Fedorko, E., \& Halverson, J. (2010). Pollution sources and mortality rates acrossrural-urban areas in the United States. The Journal of Rural Health, 26, 383-391. http://dx.doi.org/10.1111/j.1748-0361.2010.00305.x

Hwang, H. M., Park, E. K., Young, T. M., \& Hammock, B. D. (2008). Occurrence of endocrine-disrupting chemicals in indoor dust.Science of the Total Environment, 404(1), 26-35. http://dx.doi.org/10.1016/j.scitotenv.2008.05.031

Isikli, B., Demir, T. A., Akar, T., Berber, A., Urer, S. M., Kalyoncu, C., \& Canbek, M. (2012). Cadmium exposure from the cement dust emissions: A field study in a rural residence. Chemosphere, 63(9), 1546-1552. http://dx.doi.org/10.1016/j.chemosphere.2005.09.059

Jarup, L. (2003). Land contamination and renal dysfunction. Occupational and Environmental Medicine, 60, 461-462. http://dx.doi.org/10.1136/oem.60.7.461

Johnson, W. M., Ferguson, A., Hager, P., Sanou, A., \&Shenoda, D. (2006). Development of a data acquisition system for the measurement of residue transfer coefficient presented at the annual American Society for Engineering Education Conference and Exposition in Chicago, IL, Paper No. 2006-2429.

Johnson, W. M., Ferguson, A., Hager, P., Sanou, A., \& Shenoda, D. (2007). Calibration of a pneumatic system for an apparatus for measurement of surface residue transfer coefficient. American Society of Mechanical Engineers Early Career Technical Journal, 6(5.1), 5.7.

Kuo, C. Y., Wang, J. Y., Yeh, C. J., Kuo, C. W., \& Chou, H. L. (2010). Metal exposure for residents neardieseltransport routes. Journal of Environmental Science and Health, Environmental Carcinogenesis \& Ecotoxicology Reviews, 28(1), 22-38. http://dx.doi.org/10.1080/10590500903585374

Link, L., Lukens, S., \& Bush, M. A. (1995). Spherical grip strength in children 3 to 6 years of age.American Journal of Occupational Therapy, 49, 318-326. http://dx.doi.org/10.5014/ajot.49.4.318

National Center for Environmental Assessment. (2008). Anexploratory study: An assessment of modeled dioxin exposure in ceramic art studios. U.S. Environmental Protection Agency, Washington, DC, EPA/600/R-06/044F.

Nawrot T., Plusquin, M., Hogervorst, J., Roels, H. A., Celis, H., Thijis, L., \& Staessen, J. A. (2006). Environmental exposure to cadmium and risk of cancer: A prospective population-based study. Lancet Oncology, 7(2), 119-1126. http://dx.doi.org/10.1016/S1470-2045(06)70545-9

Paustenback, D. J., Fehling, K., Scott, P., Harris, M., \& Kerger, B. D. (2006). Identifying soil cleanup criteria for dioxins in urban residential soils: How have 20 years of research and risk assessments experience affected the analysis. Journal of Toxicology and Environmental Health, Part B, 9, 87-145. http://dx.doi.org/10.1080/10937400500538482

Roberts, J. W., Wallance, L. A., Camann, D. E., Dickey, P., Gilbert, S. G., Lewis, R. G., \& Takaro, T. K. (2009). Monitoring and reducing exposure of infants to pollutants in house dust. Reviews of Environmental Contamination and Toxicology, 201, 1-39. http://dx.doi.org/10.1007/978-1-4419-0032-6_1 
Robertson, A., \& Dietz, J. (1988). A description of grip strength in preschool children. American Journal of Occupational Therapy, 42, 647-652. http://dx.doi.org/10.5014/ajot.42.10.647

Thorne, P. S., Cohn, R. D., May D., Arbes, S. J., \& Zeldin, D. C. (2009). Predictors of endotoxin levels in U.S. housing.Environmental Health Perspectives, 117(5), 763-771. http://dx.doi.org/10.1289/ehp.11759

U.S Environmental Protection Agency (EPA). (2007). Pilot survey of levels of polychlorinated dibenzo-p-dioxins, polychlorinated dibenzofurans, polychlorinated biphenyls, and mercury in rural soils of the U.S. environmental protection agency. United States Environmental Protection Agency, Washington, DC, $\mathrm{EPA} / 600 / \mathrm{R}-05 / 043 \mathrm{~F}$

Zartarian, V. G. (1996). Dermal exposure reduction model (Unpublished doctoral dissertation). Stanford University, Stanford, CA.

Zartarian, V. G., Ozkaynak, H., Burke, J. M., Zufall, M. J., Rigas, M. L., \& Furtaw, E. J. (2000). A modeling framework for estimating children's residential exposure and dose to chlorpyrifos via dermal residue contact and non-dietary ingestion. Environmental Health Perspectives, 108(6), 505-514. http://dx.doi.org/10.1289/ehp.00108505 